\title{
Low-Power Ultrasounds as a Tool to Culture Human Osteoblasts inside Cancellous Hydroxyapatite
}

\author{
Lorenzo Fassina, ${ }^{1,2}$ Enrica Saino, ${ }^{2,3}$ Maria Gabriella Cusella De Angelis, ${ }^{2,4}$ \\ Giovanni Magenes, ${ }^{1,2}$ Francesco Benazzo, ${ }^{2,5}$ and Livia Visai ${ }^{2,3}$ \\ ${ }^{1}$ Dipartimento di Informatica e Sistemistica, University of Pavia, 27100 Pavia, Italy \\ ${ }^{2}$ Centre for Tissue Engineering (C.I.T.), University of Pavia, 27100 Pavia, Italy \\ ${ }^{3}$ Dipartimento di Biochimica, University of Pavia, 27100 Pavia, Italy \\ ${ }^{4}$ Dipartimento di Medicina Sperimentale, University of Pavia, 27100 Pavia, Italy \\ ${ }^{5}$ Dipartimento SMEC, IRCCS San Matteo, University of Pavia, 27100 Pavia, Italy
}

Correspondence should be addressed to Lorenzo Fassina, lorenzo.fassina@unipv.it

Received 4 January 2010; Accepted 30 January 2010

Academic Editor: Spyros Perlepes

Copyright (C) 2010 Lorenzo Fassina et al. This is an open access article distributed under the Creative Commons Attribution License, which permits unrestricted use, distribution, and reproduction in any medium, provided the original work is properly cited.

\begin{abstract}
Bone graft substitutes and cancellous biomaterials have been widely used to heal critical-size long bone defects due to trauma, tumor resection, and tissue degeneration. In particular, porous hydroxyapatite is widely used in reconstructive bone surgery owing to its biocompatibility. In addition, the in vitro modification of cancellous hydroxyapatite with osteogenic signals enhances the tissue regeneration in vivo, suggesting that the biomaterial modification could play an important role in tissue engineering. In this study, we have followed a tissue-engineering strategy where ultrasonically stimulated SAOS-2 human osteoblasts proliferated and built their extracellular matrix inside a porous hydroxyapatite scaffold. The ultrasonic stimulus had the following parameters: average power equal to $149 \mathrm{~mW}$ and frequency of $1.5 \mathrm{MHz}$. In comparison with control conditions, the ultrasonic stimulus increased the cell proliferation and the surface coating with bone proteins (decorin, osteocalcin, osteopontin, type-I collagen, and type-III collagen). The mechanical stimulus aimed at obtaining a better modification of the biomaterial internal surface in terms of cell colonization and coating with bone matrix. The modified biomaterial could be used, in clinical applications, as an implant for bone repair.
\end{abstract}

\section{Introduction}

One of the key challenges in reconstructive bone surgery is to provide living constructs that possess the ability to integrate in the surrounding tissue. Bone graft substitutes, such as autografts, allografts, xenografts, and porous biomaterials have been widely used to heal critical-size long bone defects due to trauma, tumor resection, and tissue degeneration. The biomaterials used to build 3D scaffolds for bone tissue engineering are, for instance, the hydroxyapatite [1], the partially demineralized bone [2], biodegradable porous polymer-ceramic matrices [3], and bioactive glasses $[4,5]$.

The preceding osteoinductive and osteoconductive biomaterials are ideal in order to follow a typical approach of the tissue engineering, an approach that involves the seeding and the in vitro culturing of cells within a cancellous scaffold before the implantation.

The tissue-engineering method is of great importance. In order to overcome the drawbacks associated with the standard culture systems in vitro, such as limited diffusion and inhomogeneous cell-matrix distribution, several bioreactors have been designed to provide different physical stimuli: a rotating vessel bioreactor [6], a perfusion bioreactor [7], or an electromagnetic bioreactor [8], for instance. The ideal feature of a bioreactor is the supplying of suitable levels of oxygen, nutrients, cytokines, growth factors, and appropriate physical stimuli, in order to populate, with living bone cells and mineralized extracellular matrix, the volume of a porous biomaterial for reconstructive bone surgery: this living and biocompatible tissue-engineering construct could 
be implanted together with the insertion of a vascular pedicle [9].

Gorna and Gogolewski $[10,11]$ have drawn attention to the ideal features of a bone graft substitute: it should be porous with interconnected pores of adequate size (at least $200 \mu \mathrm{m}$ ) allowing for the ingrowth of capillaries and perivascular tissues; it should attract mesenchymal stem cells from the surrounding bone and promote their differentiation into osteoblasts; it should avoid shear forces at the interface between bone and bone graft substitute; it should be biodegradable.

In this study, following the preceding "golden rules" of Gorna and Gogolewski, we have elected porous hydroxyapatite [12-14] as cancellous bone graft substitute and, using an ultrasonic stimulation [15], we have attempted to populate it with extracellular matrix and osteoblasts, of which cell function can be ultrasonically modulated [15].

Hydroxyapatite is widely used in reconstructive bone surgery owing to its biocompatibility. The in vitro modification of porous hydroxyapatite, with osteogenic signals of the transforming growth factor- $\beta$ superfamily and with bone morphogenetic proteins, enhances the tissue regeneration in vivo [16], suggesting that the modification of hydroxyapatite could play an important role in tissue engineering.

As consequence, aiming, in a future work, at accelerated and enhanced bone regeneration in vivo, in the present study of tissue engineering, we show a particular "biomimetic strategy" that consists in the in vitro modification of porous hydroxyapatite with proliferated osteoblasts and their extracellular matrix produced in situ. In other words, applying an ultrasonic wave [15], our aim was to enhance a bone cell culture inside cancellous hydroxyapatite, that is, to coat the hydroxyapatite internal surface with physiological and biocompatible cell-matrix layers. Using this approach, the in vitro cultured material could be theoretically used, in clinical applications, as an osteointegrable implant.

\section{Materials and Methods}

2.1. Hydroxyapatite Disks. Porous Orthoss bovine hydroxyapatite disks (diameter, $8 \mathrm{~mm}$; height, $4 \mathrm{~mm}$ ) were kindly provided by Geistlich Pharma AG (Wolhusen, Switzerland) [12-14]. The biomaterial had the following characteristics: internal surface area of $97 \mathrm{~m}^{2} / \mathrm{g}$, average porosity equal to $60 \%$, crystal dimensions of $10 \div 60 \mathrm{~nm}$, and $\mathrm{Ca} / \mathrm{P}$ ratio equal to 2.03 , as in normal human cancellous bone (Figure 1).

2.2. Cells. The human osteosarcoma cell line SAOS-2 was obtained from the American Type Culture Collection (HTB85, ATCC, Rockville, MD). The cells were cultured in McCoy's 5A modified medium with L-glutamine and HEPES (Cambrex Bio Science Baltimore, Inc., Baltimore, MD), supplemented with $15 \%$ fetal bovine serum, $2 \%$ sodium pyruvate, $1 \%$ antibiotics, $10^{-8} \mathrm{M}$ dexamethasone, and $10 \mathrm{mM} \beta$-glycerophosphate (Sigma-Aldrich, Inc., Milwaukee, WI). Ascorbic acid, another osteogenic supplement, is a component of McCoy's 5A modified medium. The cells were cultured at $37^{\circ} \mathrm{C}$ with $5 \% \mathrm{CO}_{2}$, routinely trypsinized

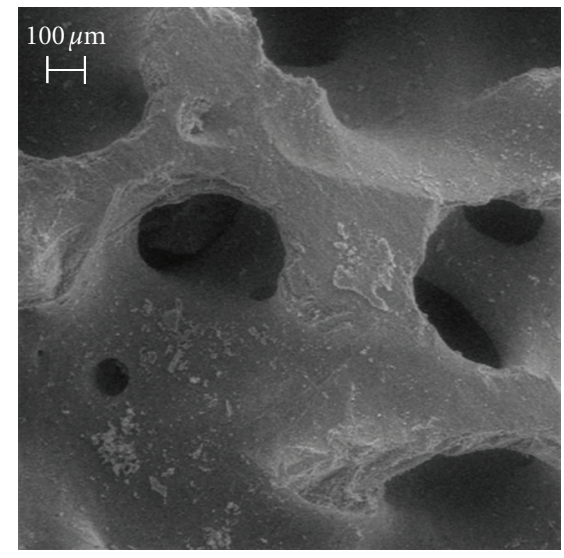

FIGURE 1: SEM image of unseeded hydroxyapatite, bar equal to $100 \mu \mathrm{m}$.

after confluency, counted, and seeded onto the hydroxyapatite disks.

2.3. Cell Seeding. In order to anchor the hydroxyapatite disks to two standard well-plates, $3 \%(\mathrm{w} / \mathrm{v})$ agarose solution was prepared and sterilized in autoclave, and during cooling, at $45^{\circ} \mathrm{C}, 100 \mu \mathrm{L}$ of agarose solution were poured inside the wells to hold the placed hydroxyapatite disks and to fix them after completed cooling.

The well-plates with the biomaterial disks were sterilized by ethylene oxide at $38^{\circ} \mathrm{C}$ for 8 hours at $65 \%$ relative humidity. After 24 hours of aeration in order to remove the residual ethylene oxide, the disks were ready inside the two culture systems: the "static," that is, the control well-plate without external stimulus and the "ultrasonic," that is, the ultrasonically stimulated well-plate.

A cell suspension of $10 \times 10^{6}$ cells in $400 \mu \mathrm{L}$ was added onto the top of each disk and, after 0.5 hour, $600 \mu \mathrm{L}$ of culture medium was added to cover the disks. Cells were allowed to attach overnight, then the static culture was continued in the standard well-plate and the ultrasound stimulation was applied for the first time.

2.4. Ultrasound Stimulation. An ultrasound stimulus [15] was applied through the culture medium by a FAST ultrasound generator (Igea, Carpi, Italy) to the seeded hydroxyapatite disks. The mechanical wave had the following characteristics: signal frequency equal to $1.5 \pm 0.03 \mathrm{MHz}$, duty cycle of $200 \pm 4 \mu \mathrm{s}$, repetition rate equal to $1 \pm$ $0.02 \mathrm{kHz}$, and temporal average power of $149 \pm 3 \mathrm{~mW}$. Lowintensity ultrasound stimulus accelerates the fracture healing in clinical studies [17].

The ultrasonic culture was placed into a standard cell culture incubator with an environment of $37^{\circ} \mathrm{C}$ and $5 \% \mathrm{CO}_{2}$, and it was stimulated $20 \mathrm{~min} /$ day for a total of 22 days. The culture medium was changed on days $4,7,10,13,16$, and 19 .

2.5. Standard Well-Plate Culture. The static culture was placed into a standard cell culture incubator. The duration 


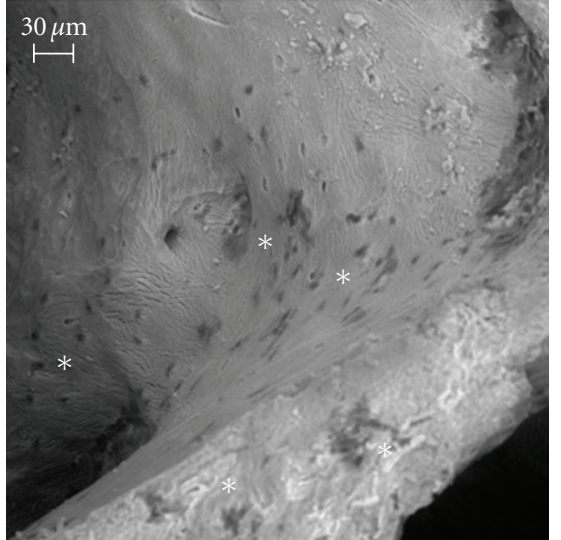

FIgUre 2: SEM image of the static culture, bar equal to $30 \mu \mathrm{m}$. The osteoblasts are in the "backscattered depressions" near the juxtaposed asterisks: at the end of the culture period, statically cultured cells were few and, essentially, not surrounded by extracellular matrix; therefore, wide biomaterial regions remained devoid of cellmatrix complexes.

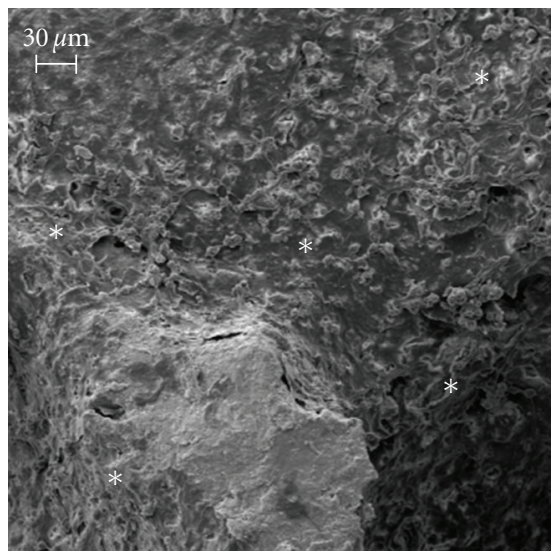

Figure 3: SEM image of the ultrasonic culture, bar equal to $30 \mu \mathrm{m}$. During the culture period, the physical stimulus caused a wideranging coat of the internal surface of the biomaterial: several osteoblasts proliferated and the biomaterial was tending to be hidden by cell-matrix layers (asterisks).

of the static culture was 22 days and the culture medium was changed on days $4,7,10,13,16$, and 19 .

2.6. Scanning Electron Microscopy (SEM) Analysis. At the end of the culture period, the disks were fixed with $2.5 \%(\mathrm{v} / \mathrm{v})$ glutaraldehyde solution in $0.1 \mathrm{M} \mathrm{Na}$-cacodylate buffer $(\mathrm{pH}=$ 7.2) for 1 hour at $4^{\circ} \mathrm{C}$, washed with $\mathrm{Na}$-cacodylate buffer, and then dehydrated at room temperature in a gradient ethanol series up to $100 \%$. The samples were kept in 100\% ethanol for 15 minutes, and then critical point-dried with $\mathrm{CO}_{2}$. The specimens were mounted on aluminum stubs, sputter coated with gold (degree of purity equal to 99\%), and then observed with a Leica Cambridge Stereoscan microscope (Leica Microsystems, Bensheim, Germany).
2.7. DNA Content. At the end of the culture period, the cells were lysed by a freeze-thaw method in sterile deionized distilled water and the released DNA content was evaluated with a fluorometric method (PicoGreen, Molecular Probes, Eugene, OR). A DNA standard curve [15], obtained from a known amount of osteoblasts, was used to express the results as cell number per disk.

2.8. Set of Rabbit Polyclonal Antisera. Fisher et al. (http:// csdb.nidcr.nih.gov/csdb/antisera.htm, National Institutes of Health, National Institute of Dental and Craniofacial Research, Craniofacial and Skeletal Diseases Branch, Matrix Biochemistry Unit, Bethesda, MD) presented us, generously, with the following rabbit polyclonal antibody immunoglobulins G: antiosteocalcin, anti-type-I collagen, anti-type-III collagen, antidecorin, and antiosteopontin (antiserum LF32, LF-67, LF-71, LF-136, and LF-166, respectively) [18].

2.9. Set of Purified Proteins. Decorin [19], osteocalcin (immunoenzymatic assay kit, BT-480, Biomedical Technologies, Inc., Stoughton, MA), osteopontin (immunoenzymatic assay kit, 900-27, Assay Designs, Inc., Ann Arbor, MI), type-I collagen [20], and type-III collagen (Sigma-Aldrich) were used.

2.10. Confocal Microscopy. At the end of the culture period, the disks were fixed with $4 \%(\mathrm{w} / \mathrm{v})$ paraformaldehyde solution in $0.1 \mathrm{M}$ phosphate buffer $(\mathrm{pH}=7.4)$ for 8 hours at room temperature and washed with PBS $(137 \mathrm{mM} \mathrm{NaCl}$, $2.7 \mathrm{mM} \mathrm{KCl}, 4.3 \mathrm{mM} \mathrm{Na}_{2} \mathrm{HPO}_{4}, 1.4 \mathrm{mM} \mathrm{KH}_{2} \mathrm{PO}_{4}, \mathrm{pH}=7.4$ ) three times for 15 minutes. The disks were then blocked by incubating with PAT (PBS containing 1\% [w/v] bovine serum albumin and $0.02 \%[\mathrm{v} / \mathrm{v}]$ Tween 20 ) for 2 hours at room temperature and washed.

L. Fisher's antidecorin, antiosteocalcin, antiosteopontin, anti-type-I collagen, and anti-type-III collagen rabbit polyclonal antisera were used as primary antibodies with a dilution equal to $1: 1000$ in PAT. The incubation with the primary antibodies was performed overnight at $4^{\circ} \mathrm{C}$, whereas the negative controls were based upon the incubation, overnight at $4^{\circ} \mathrm{C}$, with PAT instead of the primary antibodies. The disks and the negative controls were washed and incubated with Alexa Fluor 488 goat antirabbit IgG $(\mathrm{H}+\mathrm{L})$ (Molecular Probes) with a dilution of $1: 500$ in PAT for 1 hour at room temperature.

At the end of the incubation, the disks were washed in PBS, counterstained with Hoechst solution $(2 \mu \mathrm{g} / \mathrm{mL})$ to target the cellular nuclei, and then washed. The images were taken by blue excitation with a confocal microscope (TCS SPII, Leica Microsystems) equipped with a digital image capture system at $100 \times$ magnification.

2.11. Extraction of the Extracellular Matrix Proteins from the Cultured Disks and Enzyme-Linked Immunosorbent Assay (ELISA). At the end of the culture period, in order to evaluate the amount of the extracellular matrix constituents over the internal and external hydroxyapatite surfaces, the disks 
were washed extensively with sterile PBS (137 mM NaCl, $2.7 \mathrm{mM} \mathrm{KCl}, 4.3 \mathrm{mM} \mathrm{Na}_{2} \mathrm{HPO}_{4}, 1.4 \mathrm{mM} \mathrm{KH}_{2} \mathrm{PO}_{4}, \mathrm{pH}=7.4$ ) in order to remove the culture medium, and then incubated for 24 hours at $37^{\circ} \mathrm{C}$ with $1 \mathrm{~mL}$ of sterile sample buffer $(1.5 \mathrm{M}$ Tris- $\mathrm{HCl}, 60 \%[\mathrm{w} / \mathrm{v}]$ sucrose, $0.8 \%[\mathrm{w} / \mathrm{v}]$ sodium dodecyl sulphate, $\mathrm{pH}=8.0$ ). At the end of the incubation period, the sample buffer aliquots were removed, and then the disks were centrifuged at $4000 \mathrm{rpm}$ for 15 minutes in order to collect the sample buffer entrapped into the pores. The total protein concentration in the two culture systems was evaluated by the BCA Protein Assay Kit (Pierce Biotechnology, Inc., Rockford, IL). The total protein concentration was $749 \pm 108 \mu \mathrm{g} / \mathrm{mL}$ in the static culture and $1527 \pm 274 \mu \mathrm{g} / \mathrm{mL}$ in the ultrasonic culture $(P<.05)$. After matrix extraction, the disks were incubated, once again, for 24 hours at $37^{\circ} \mathrm{C}$ with $1 \mathrm{~mL}$ of sterile sample buffer, and no protein content was detected.

Calibration curves to measure decorin, osteocalcin, osteopontin, type-I collagen, and type-III collagen were performed. Microtiter wells were coated with increasing concentrations of each purified protein, from $1 \mathrm{ng}$ to $2 \mu \mathrm{g}$, in coating buffer $\left(50 \mathrm{mM} \mathrm{Na} \mathrm{CO}_{3}, \mathrm{pH}=9.5\right)$ overnight at $4^{\circ} \mathrm{C}$. Some of the wells were coated with bovine serum albumin (BSA) as a negative control. In order to measure the extracellular matrix amount of each protein by an ELISA, microtiter wells were coated, overnight at $4^{\circ} \mathrm{C}$, with $100 \mu \mathrm{L}$ of the extracted extracellular matrix $(20 \mu \mathrm{g} / \mathrm{mL}$ in coating buffer). After three washes with PBST (PBS containing $0.1 \%$ [v/v] Tween 20), the wells were blocked by incubating with $200 \mu \mathrm{L}$ of PBS containing 2\% (w/v) BSA for 2 hours at $22^{\circ} \mathrm{C}$. The wells were subsequently incubated for 1.5 hours at $22^{\circ} \mathrm{C}$ with $100 \mu \mathrm{L}$ of the L. Fisher's antidecorin, antiosteocalcin, antiosteopontin, anti-type-I collagen, and anti-type-III collagen rabbit polyclonal antisera (1:500 dilution in 1\% BSA). After washing, the wells were incubated for 1 hour at $22^{\circ} \mathrm{C}$ with $100 \mu \mathrm{L}$ of HRP-conjugated goat anti-rabbit IgG ( 1 : 1000 dilution in $1 \% \mathrm{BSA})$.

The wells were finally incubated with $100 \mu \mathrm{L}$ of development solution (phosphate-citrate buffer with $o$ phenylenediamine dihydrochloride substrate). The color reaction was stopped with $100 \mu \mathrm{L}$ of $0.5 \mathrm{M} \mathrm{H}_{2} \mathrm{SO}_{4}$ and the absorbance values were measured at $490 \mathrm{~nm}$ with a microplate reader (Bio-Rad Laboratories, Inc., Hercules, CA). The amount of extracellular matrix constituents inside the disks is expressed as $\mathrm{fg} /($ cell $\times$ disk).

2.12. Statistics. The disks number was 24 in each repeated experiment (12 disks in the control culture and 12 disks in the ultrasonic culture). The experiment was repeated 4 times. Results are expressed as mean \pm standard deviation. In order to compare the results between the two culture systems, one-way analysis of variance (ANOVA) with post hoc Bonferroni test was applied, electing a significance level of 0.05 .

\section{Results}

The human SAOS-2 osteoblasts were seeded onto porous hydroxyapatite disks, and then cultured without or with an ultrasonic stimulus for 22 days. These culture methods permitted the study of the SAOS- 2 cells as they modified the biomaterial through the proliferation and the coating with extracellular matrix. The cell-matrix distribution was compared between the two culture systems.

3.1. Microscope Analysis. In comparison to control condition, SEM images revealed that, due to the ultrasound stimulus, the osteoblasts proliferated and built their extracellular matrix over the available internal hydroxyapatite surface (Figures 2 and 3). At the end of the culture period, statically cultured cells were few and, essentially, not surrounded by extracellular matrix, therefore wide biomaterial regions remained devoid of cell-matrix complexes (Figure 2). In contrast, the physical stimulus caused a wide-ranging coat of the internal surface of the biomaterial: several osteoblasts proliferated and the biomaterial was tending to be hidden by cell-matrix layers (Figure 3).

The immunolocalization of type-I collagen and decorin with the counterstaining of the cellular nuclei showed the stimulation effects in terms of higher cell proliferation and more intense building of the extracellular matrix (Figures 4 and 5). The immunolocalization of osteocalcin, osteopontin, and type-III collagen revealed similar results (data not shown).

These observations were confirmed by the measure of the DNA content at the end of the culture period: in the static culture, the cell number per disk grew to $22.1 \times 10^{6} \pm 3.2 \times 10^{4}$ and in the ultrasonic culture to $34.7 \times 10^{6} \pm 3.9 \times 10^{4}$ with $P<.05$.

3.2. Extracellular Matrix Extraction. In order to evaluate the amount of bone extracellular matrix inside the hydroxyapatite disks, an ELISA of the extracted matrix was performed: at the end of the culture period, in comparison with the static culture, the ultrasound stimulation significantly increased the internal surface coating with decorin, osteocalcin, osteopontin, type-I collagen, and type-III collagen $(P<.05)$ (Table 1).

\section{Discussion}

The aim of this study was the in vitro modification of a porous hydroxyapatite with extracellular matrix and osteoblasts to make the biomaterial more biocompatible for the bone repair in vivo.

A discussion about the concept of "biocompatibility" is necessary. When a biomaterial is implanted in a biological environment, a nonphysiologic layer of adsorbed proteins mediates the interaction of the surrounding host cells with the material surface. The body interprets this protein layer as a foreign invader that must be walled off in an avascular and tough collagen sac. Therefore, the biomedical surfaces must be developed so that the host tissue can recognize them as "self". Castner and Ratner think the "biocompatible surfaces" of the "biomaterials that heal" as the surfaces with the characters of a "clean, fresh wound" [21]: these "selfsurfaces" could obtain a physiological inflammatory reaction 


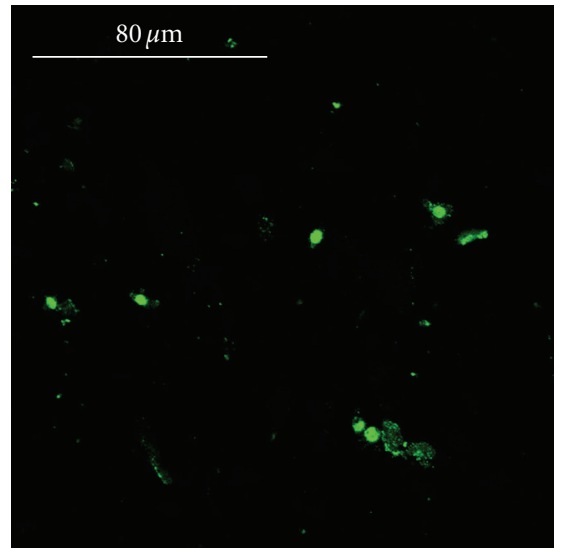

(a)

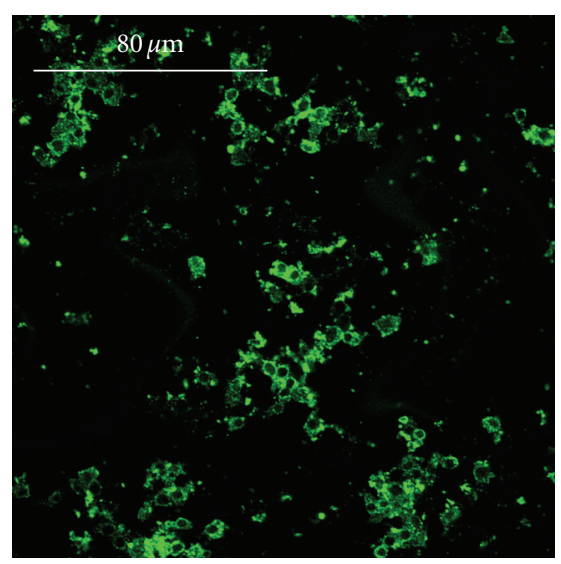

(c)

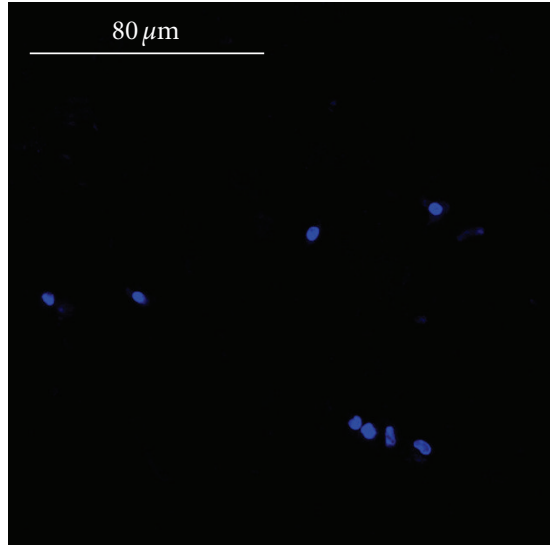

(b)

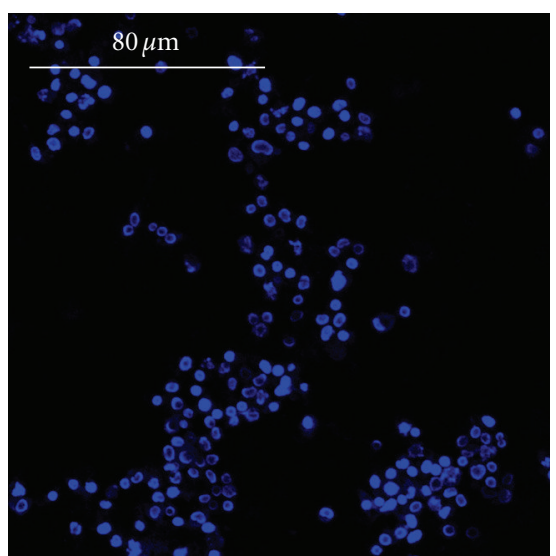

(d)

FIGURE 4: Immunolocalization of type-I collagen (panels a and c, green) and cellular nuclei (panels b and d, blue) in the static culture (panels $\mathrm{a}$ and b) and in the ultrasonic culture (panels c and d), bars equal to $80 \mu \mathrm{m}$. During the culture period, in the control (panels a and b), the osteoblasts built a scanty amount of bone matrix, whereas, in the stimulated culture (panels $\mathrm{c}$ and $\mathrm{d}$ ), the osteoblasts secreted a wide amount of matrix. The immunolocalization of osteocalcin, osteopontin, and type-III collagen revealed similar results.

TABLE 1: Amount of extracellular matrix constituents inside hydroxyapatite.

\begin{tabular}{lccc}
\hline & \multicolumn{2}{c}{ Matrix protein total coating after 22 days of culture in fg/(cell $\times$ disk $)$} \\
& Static culture & Ultrasonic culture & Ultrasonic /Static \\
\hline Decorin & $5.58 \pm 0.22$ & $15.25 \pm 0.42$ & 2.73 -fold \\
Osteocalcin & $1.79 \pm 0.33$ & $5.76 \pm 0.39$ & 3.22 -fold \\
Osteopontin & $1.75 \pm 0.73$ & $3.04 \pm 0.47$ & 1.74 -fold \\
Type-I collagen & $3.72 \pm 0.49$ & $16.85 \pm 0.95$ & 4.53 -fold \\
Type-III collagen & $4.59 \pm 0.13$ & $11.04 \pm 0.71$ & 2.40 -fold \\
\hline
\end{tabular}

Table note: $P<.05$ in all "Static" versus "Ultrasonic" comparisons.

leading to normal healing. In this study, we have followed a biomimetic strategy where the seeded osteoblasts built a biocompatible surface made of bone matrix $[15,22]$.

To enhance the coating of the biomaterial internal surface, an ultrasonic wave was applied to the seeded biomaterial [15]. The ultrasound stimulus increased the cell proliferation around 1.6-fold. Furthermore, the ultrasonic wave significantly enhanced the synthesis of type-I collagen, decorin, osteopontin, osteocalcin, and type-III collagen, which are fundamental constituents of the physiological bone matrix: in particular, type-I collagen is the most important and abundant structural protein of the bone matrix; decorin is a proteoglycan considered a key regulator for the assembly and the function of many extracellular matrix proteins with a major role in the lateral growth of the collagen fibrils, delaying the lateral assembly on the surface of the fibrils; osteopontin is an extracellular glycosylated bone phosphoprotein secreted at the early stages 


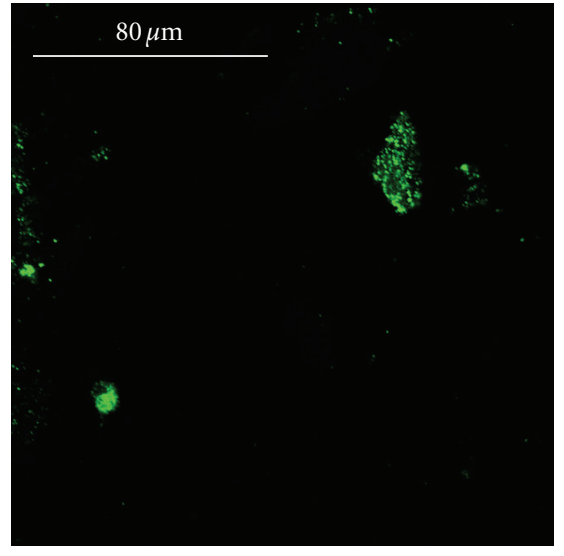

(a)

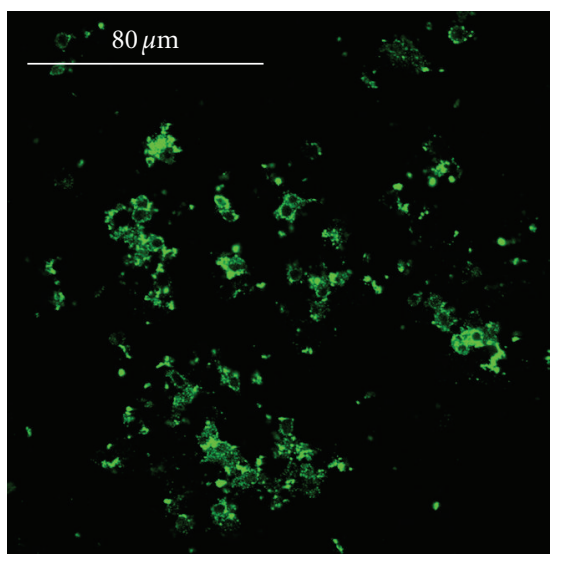

(c)

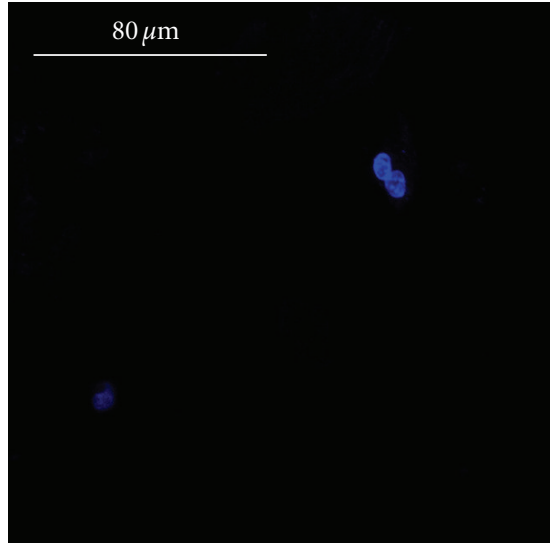

(b)

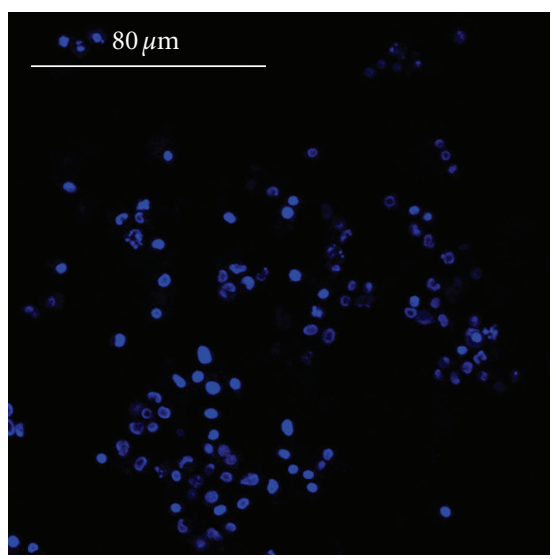

(d)

Figure 5: Immunolocalization of decorin (panels a and c, green) and cellular nuclei (panels b and d, blue) in the static culture (panels $\mathrm{a}$ and $\mathrm{b}$ ) and in the ultrasonic culture (panels $\mathrm{c}$ and d), bars equal to $80 \mu \mathrm{m}$. During the culture period, in the control (panels a and b), the osteoblasts produced a very little amount of decorin, a key regulator for matrix spatial organization, whereas, in the stimulated culture (panels $\mathrm{c}$ and $\mathrm{d}$ ), the osteoblasts secreted a larger amount of $3 \mathrm{D}$ organized bone matrices.

of the osteogenesis before the onset of the mineralization, it binds calcium, it is likely to be involved in the regulation of the hydroxyapatite crystal growth, and, through specific interaction with the vitronectin receptor, it promotes the attachment of the cells to the matrix; osteocalcin is secreted after the onset of mineralization and it binds to bone minerals.

The preceding results could be explained with a signaling model. The ultrasound stimulation raises the net $\mathrm{Ca}^{2+}$ flux in the osteoblast cytosol and the release of the intracellular $\mathrm{Ca}^{2+}$ [23-25]. According to Pavalko's signaling model, the increase of the cytosolic $\mathrm{Ca}^{2+}$ concentration is the starting point of signaling pathways, which cause the secretion of prostaglandins enhancing the osteoblast proliferation, and which target specific bone matrix genes [23].

Consistent with Pavalko's model, mechanically stimulated osteoblasts produce autocrine and paracrine prostaglandin signal for cell proliferation; the same mechanically stimulated osteoblasts produce bone extracellular matrix. Prostaglandins are released in the culture medium, whereas the proteins are deposited onto the biomaterial. Even if prostaglandins and proteins have partially common biochemical pathways [23], they have a different geometrical destination: the medium and the material surface, respectively. For that reason, the efficiency in prostaglandin action (cell proliferation enhancement of 1.6-fold) was different from the efficiency of matrix deposition (biomaterial coating enhancement of $1.7 \div 4.5$-fold as in Table 1 ).

In this study, the ultrasonic stimulus was a physical method to obtain the biomimetic modification of the material, whose internal surface was coated by osteoblasts and by a layer of bone matrix. The use of a cell line showed the potential of the ultrasound stimulation; nevertheless, appropriately tuning the parameters of the ultrasonic wave, the stimulus duration, and the culture time, a better result could be obtained with autologous bone marrow stromal cells instead of SAOS-2 osteoblasts for total immunocompatibility with the patient. In addition, after the in vivo implantation of the cultured cancellous hydroxyapatite, an ultrasound therapy could be applied with the same wave parameters [15] to enhance the patient healing [17]. 
In conclusion, we theorize that the cultured "self-surface" could be used fresh, that is, rich in autologous cells and matrix, or after sterilization with ethylene oxide, that is, rich only in autologous matrix. In future work, we intend to use our constructs, which are rich in autologous matrix, as a simple, storable, tissue-engineering product for the bone repair [22].

\section{Acknowledgments}

The authors thank L. W. Fisher, K. Martin, S. Setti, R. Cadossi, A. Mortara, D. Picenoni, and P. Vaghi. Hydroxyapatite disks were kindly provided by Geistlich Pharma (Wolhusen, Switzerland). The FAST ultrasound generator was a gift from Igea (Carpi, Italy). This work was supported by Fondazione Cariplo Grants (2004.1424/10.8485 and 2006.0581/10.8485) to Francesco Benazzo, by PRIN Grant (2006) from Italian Ministry of Education, University and Research to Livia Visai, and by FIRB Grant (RBIP06FH7J) from Italian Ministry of Education, University and Research to Maria Gabriella Cusella De Angelis.

\section{References}

[1] M. Nishikawa, A. Myoui, H. Ohgushi, M. Ikeuchi, N. Tamai, and $\mathrm{H}$. Yoshikawa, "Bone tissue engineering using novel interconnected porous hydroxyapatite ceramics combined with marrow mesenchymal cells: quantitative and threedimensional image analysis," Cell Transplantation, vol. 13, no. 4, pp. 367-376, 2004.

[2] J. R. Mauney, J. Blumberg, M. Pirun, V. Volloch, G. VunjakNovakovic, and D. L. Kaplan, "Osteogenic differentiation of human bone marrow stromal cells on partially demineralized bone scaffolds in vitro," Tissue Engineering, vol. 10, no. 1-2, pp. 81-92, 2004.

[3] J. E. Devin, M. A. Attawia, C. T. Laurencin, et al., "Threedimensional degradable porous polymer-ceramic matrices for use in bone repair," Journal of Biomaterials Science, Polymer Edition, vol. 7, no. 8, pp. 661-669, 1996.

[4] S. Deb, R. Mandegaran, and L. Di Silvio, "A porous scaffold for bone tissue engineering/45S5 Bioglass ${ }^{\circledR}$ derived porous scaffolds for co-culturing osteoblasts and endothelial cells," Journal of Materials Science: Materials in Medicine, vol. 21, no. 3, pp. 893-905, 2010.

[5] L. Francis, D. Meng, J. C. Knowles, I. Roy, and A. R. Boccaccini, "Multi-functional $\mathrm{P}(3 \mathrm{HB})$ microsphere/45S5 Bioglass ${ }^{\circledR}$ based composite scaffolds for bone tissue engineering," Acta Biomaterialia. In press.

[6] E. A. Botchwey, S. R. Pollack, E. M. Levine, and C. T. Laurencin, "Bone tissue engineering in a rotating bioreactor using a microcarrier matrix system," Journal of Biomedical Materials Research, vol. 55, no. 2, pp. 242-253, 2001.

[7] L. Fassina, L. Visai, L. Asti, et al., "Calcified matrix production by SAOS-2 cells inside a polyurethane porous scaffold, using a perfusion bioreactor," Tissue Engineering, vol. 11, no. 5-6, pp. 685-700, 2005.

[8] L. Fassina, L. Visai, F. Benazzo, et al., "Effects of electromagnetic stimulation on calcified matrix production by SAOS-2 cells over a polyurethane porous scaffold," Tissue Engineering, vol. 12, no. 7, pp. 1985-1999, 2006.
[9] S. Akita, N. Tamai, A. Myoui, et al., "Capillary vessel network integration by inserting a vascular pedicle enhances bone formation in tissue-engineered bone using interconnected porous hydroxyapatite ceramics," Tissue Engineering, vol. 10, no. 5-6, pp. 789-795, 2004.

[10] K. Gorna and S. Gogolewski, "Biodegradable polyurethanes for implants. II. In vitro degradation and calcification of materials from poly( $\varepsilon$-caprolactone)-poly(ethylene oxide) diols and various chain extenders," Journal of Biomedical Materials Research, vol. 60, no. 4, pp. 592-606, 2002.

[11] K. Gorna and S. Gogolewski, "Preparation, degradation, and calcification of biodegradable polyurethane foams for bone graft substitutes," Journal of Biomedical Materials Research, vol. 67, no. 3, pp. 813-827, 2003.

[12] E. B. Stephan, D. Jiang, S. Lynch, P. Bush, and R. Dziak, "Anorganic bovine bone supports osteoblastic cell attachment and proliferation," Journal of Periodontology, vol. 70, no. 4, pp. 364-369, 1999.

[13] R. E. Cohen, R. H. Mullarky, B. Noble, R. L. Comeau, and M. E. Neiders, "Phenotypic characterization of mononuclear cells following anorganic bovine bone implantation in rats," Journal of Periodontology, vol. 65, no. 11, pp. 1008-1015, 1994.

[14] Z. Artzi, C. E. Nemcovsky, and H. Tal, "Efficacy of porous bovine bone mineral in various types of osseous deficiencies: clinical observations and literature review," International Journal of Periodontics and Restorative Dentistry, vol. 21, no. 4, pp. 395-405, 2001.

[15] L. Fassina, E. Saino, M. S. Sbarra, et al., "Ultrasonic and electromagnetic enhancement of a culture of human SAOS2 osteoblasts seeded onto a titanium plasma-spray surface," Tissue Engineering, vol. 15, no. 2, pp. 233-242, 2009.

[16] U. Ripamonti, C. Ferretti, and M. Heliotis, "Soluble and insoluble signals and the induction of bone formation: molecular therapeutics recapitulating development," Journal of Anatomy, vol. 209, no. 4, pp. 447-468, 2006.

[17] J. D. Heckman, J. P. Ryaby, J. McCabe, J. J. Frey, and R. F. Kilcoyne, "Acceleration of tibial fracture-healing by noninvasive, low-intensity pulsed ultrasound," Journal of Bone and Joint Surgery. American, vol. 76, no. 1, pp. 26-34, 1994.

[18] L. W. Fisher, J. T. Stubbs III, and M. F. Young, "Antisera and cDNA probes to human and certain animal model bone matrix noncollagenous proteins," Acta Orthopaedica Scandinavica, Supplement, vol. 66, no. 266, pp. 61-65, 1995.

[19] K. G. Vogel and S. P. Evanko, "Proteoglycans of fetal bovine tendon," Journal of Biological Chemistry, vol. 262, no. 28, pp. 13607-13613, 1987.

[20] A. Rossi, L. V. Zuccarello, G. Zanaboni, et al., "Type I collagen CNBr peptides: species and behavior in solution," Biochemistry, vol. 35, no. 19, pp. 6048-6057, 1996.

[21] D. G. Castner and B. D. Ratner, "Biomedical surface science: foundations to frontiers," Surface Science, vol. 500, no. 1-3, pp. 28-60, 2002.

[22] L. Fassina, L. Visai, M. G. Cusella De Angelis, F. Benazzo, and G. Magenes, "Surface modification of a porous polyurethane through a culture of human osteoblasts and an electromagnetic bioreactor," Technology and Health Care, vol. 15, no. 1, pp. 33-45, 2007.

[23] F. M. Pavalko, S. M. Norvell, D. B. Burr, C. H. Turner, R. L. Duncan, and J. P. Bidwell, "A model for mechanotransduction in bone cells: the load-bearing mechanosomes," Journal of Cellular Biochemistry, vol. 88, no. 1, pp. 104-112, 2003. 
[24] Y. Khan and C. T. Laurencin, "Fracture repair with ultrasound: clinical and cell-based evaluation," Journal of Bone and Joint Surgery. American, vol. 90, supplement 1, pp. 138-144, 2008.

[25] J. K. Li, J. Lin, H. C. Liu, et al., "Comparison of ultrasound and electromagnetic field effects on osteoblast growth," Ultrasound in Medicine and Biology, vol. 32, no. 5, pp. 769-775, 2006. 


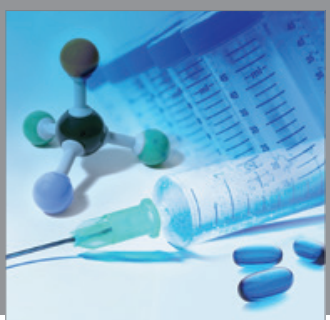

International Journal of

Medicinal Chemistry

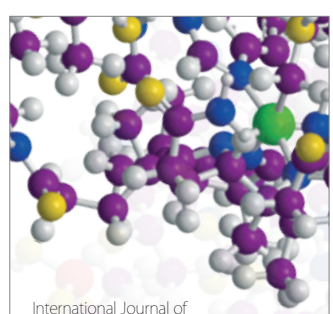

Carbohydrate Chemistry

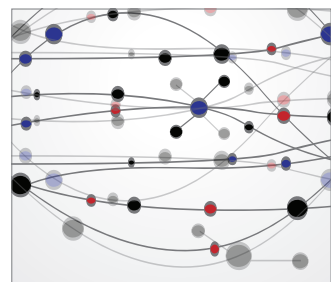

The Scientific World Journal
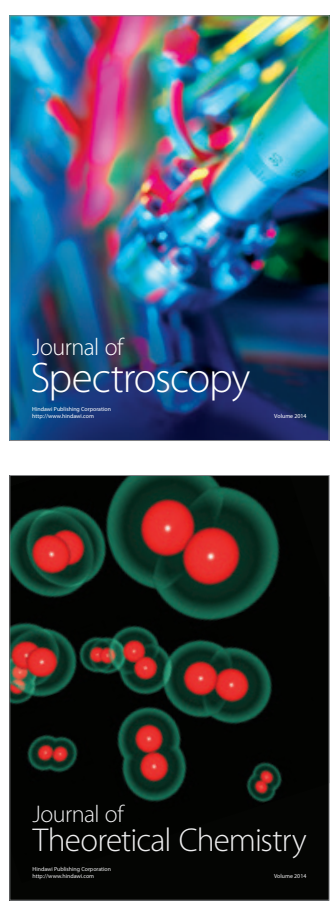
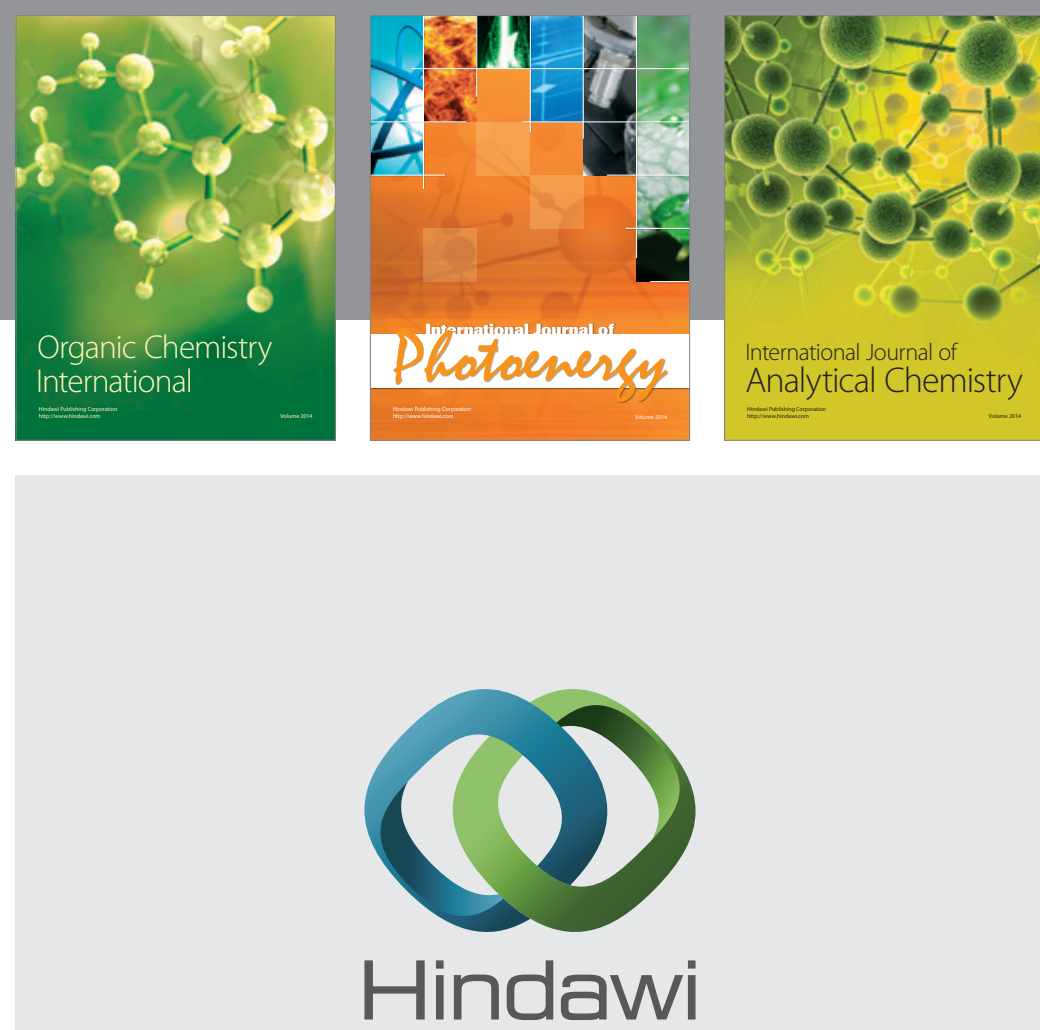

Submit your manuscripts at

http://www.hindawi.com
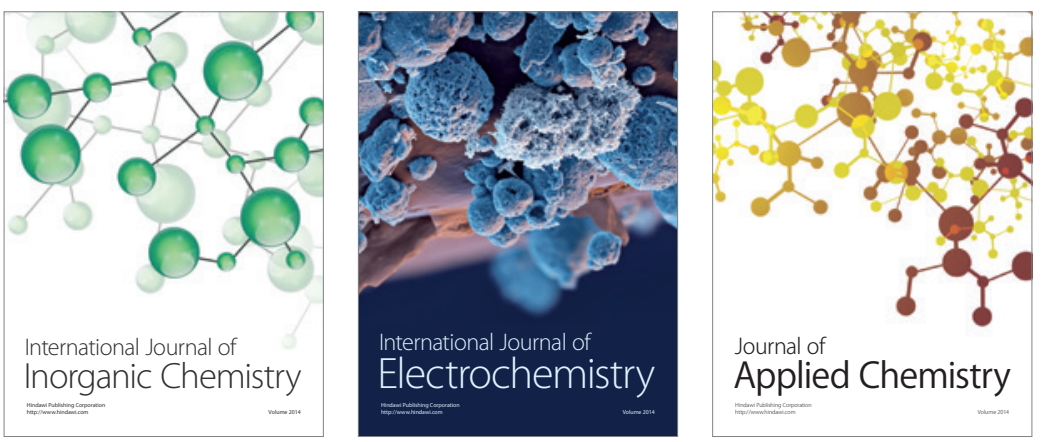

Journal of

Applied Chemistry
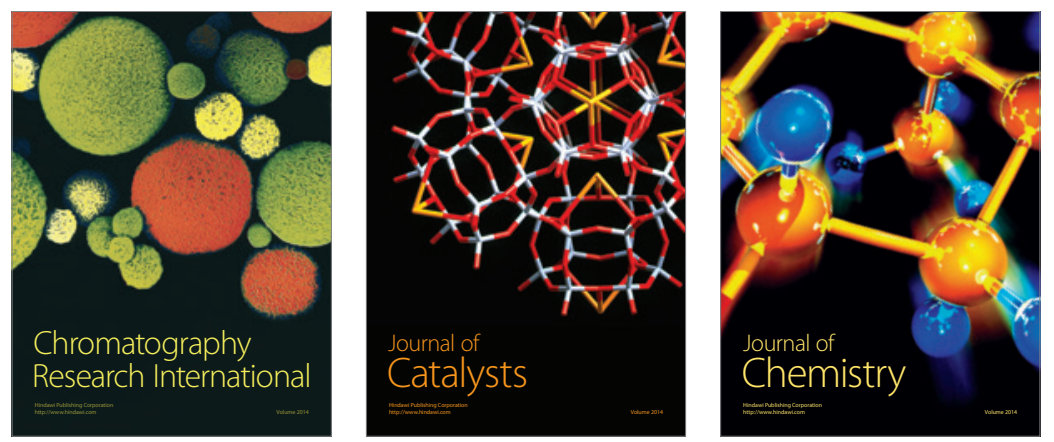
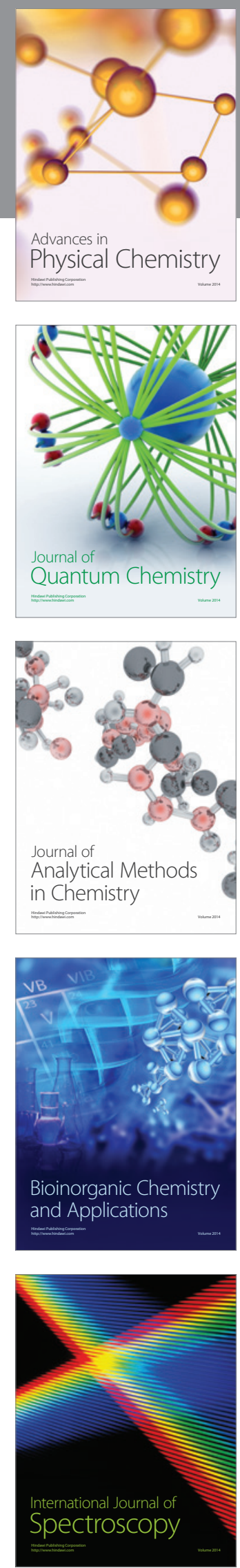